\title{
Transforaminal lumbar interbody fusion (TLIF) versus posterior lumbar interbody fusion (PLIF) in the treatment of single-level lumbar spondylolisthesis
}

\author{
Essam Moneer Ali Rezk ${ }^{*}$ (D, Ahmed Rizk Elkholy and Ebrahim Ahmed Shamhoot
}

\begin{abstract}
Background: Various surgical procedures have been recommended for the treatment of lumbar spondylolisthesis, but controversy still exists regarding the optimal surgical technique. In this study, we compared the clinical and radiologic outcomes of posterior lumbar interbody fusion (PLIF) and transforaminal lumbar interbody fusion (TLIF) with pedicle screw fixation in the treatment of single-level lumbar spondylolisthesis.

Methods: Ninety-four patients underwent lumbar interbody fusion with pedicle screw fixation for the treatment of adult lumbar spondylolisthesis. Forty-six had PLIF with two cages and pedicle fixation (group 1), and 48 had TLIF with one cage and pedicle fixation (group 2). The follow-up was performed clinically using the visual analog scale (VAS) and Oswestry Disability Index (ODI) Questionnaires. Outcome scores were assessed 3, 6, and 12 months after surgery. Radiographs were obtained postoperatively and at regular intervals for 6 months. Perioperative outcomes such as surgery time, blood loss, length of hospital stay, and incidence of surgical complications were also recorded.
\end{abstract}

Results: Estimated blood loss and operative time in the TLIF group were significantly lower than those in the PLIF group. VAS for back pain and ODI were significantly better in the TLIF group than the PLIF group. However, at the time of the last follow-up, both groups had similar slip reduction and spinal fusion rates. More complication rate was encountered in the PLIF group compared to the TLIF group.

Conclusions: Our study showed that TLIF is superior to PLIF with respect to functional outcome and complication rate in grade I/II single-level lumbar spondylolisthesis.

Keywords: Lumbar spondylolisthesis, Posterior lumbar interbody fusion (PLIF), Transforaminal lumbar interbody fusion (TLIF)

\section{Introduction}

Spondylolisthesis (spondylos = vertebrae; listhesis = slippage) is defined as the forward slippage of one vertebra on another [1]. Of its 5 subtypes, degenerative and isthmic spondylolisthesis are the most common in adults [2]. Both can lead to compression and instability, which result in radicular and low back pain [3].

Surgical fusion is a crucial method for stabilizing the spine in cases of lumbar spondylolisthesis; it is used to

\footnotetext{
* Correspondence: es_moneer2000@yahoo.com

Department of Neurosurgery, Faculty of Medicine, Tanta University, El-Gaish Street, Tanta, Gharbyia 31527, Egypt
}

\section{Springer Open}

(c) The Author(s). 2019 Open Access This article is distributed under the terms of the Creative Commons Attribution 4.0 International License (http://creativecommons.org/licenses/by/4.0/), which permits unrestricted use, distribution, and reproduction in any medium, provided you give appropriate credit to the original author(s) and the source, provide a link to the Creative Commons license, and indicate if changes were made.

reduce the pain in patients with chronic low back pain [4]. Different surgical fusion techniques are currently available including anterior interbody fusion, posterior interbody fusion, posterolateral fusion, and repair of the pars interarticularis [5-9].

PLIF or TLIF can achieve a circumferential spinal stabilization by the placement of pedicle screws and an interbody spacer through a single posterior approach [10-12]. There is no definitive evidence for one approach being superior to the other in terms of fusion or clinical outcomes [13]. 
The current study is a retrospective clinical case series aiming to compare the surgical results of PLIF and TLIF in the treatment of low-grade spondylolisthesis.

\section{Patients and methods}

\section{Patient population and selection criteria}

Between March 2015 and May 2018, 94 patients underwent lumbar interbody fusion with pedicle screw fixation for the treatment of adult lumbar spondylolisthesis at the Department of Neurosurgery, Tanta University Hospital. Forty-six had PLIF with two cages and pedicle fixation (group 1), and 48 had TLIF with one cage and pedicle fixation (group 2). Inclusion criteria were as follows: single-level, low-grade (Meyerding grades I or II), isthmic or degenerative spondylolisthesis, and significant back and leg pain that failed conservative management.

Exclusion criteria were spondylolisthesis grades III and IV, instrumentation of more than two levels, a history of a previous fusion surgery to the lumbar spine, concomitant deformities of the spine (scoliosis, tumor, or trauma), and osteoporosis diagnosed by means of radiography and bone mineral density examination ( $\mathrm{T}$-score $\leq 2.5$ ). Body mass index (BMI) [14] was calculated in all cases before surgery, and patients with BMI $\geq 40$ (morbid obesity) were excluded from our study.

Informed consent was obtained from all participants. The choice of a lumbar fusion technique was individualized based on clinical needs of each patient, surgeon preferences, and patients' request according to the informed consent and explanation of various surgical procedures. A summary of demographic and pre-operative data is presented in Table 1.

\section{Surgical technique}

All patients were operated under general anesthesia and in prone position. All patients had single-level fusion performed. Brace support was recommended for up to 6-8 weeks after surgery.

\section{PLIF}

A midline skin incision was used. The fascia was incised and then the paravertebral muscles were dissected from the spine. Radiographs were used to confirm the appropriate vertebral level. Bilateral pedicle screw-rod constructs were then inserted, and a laminectomy was performed at that level. This was followed by bilateral foraminotomy and discectomy, and interbody graft placement. Cartilaginous material was removed from the endplates using an endplate scraper. Interbody fusion was performed with a polyetheretherketone (PEEK) cage filled with autologous bone graft on each side. A final fluoroscopy was performed as necessary to confirm
Table 1 Patients' characteristics

\begin{tabular}{|c|c|c|}
\hline Parameters & $\begin{array}{l}\text { PLIF group } \\
(N=46)\end{array}$ & $\begin{array}{l}\text { TLIF group } \\
(N=48)\end{array}$ \\
\hline \multicolumn{3}{|l|}{ Age (years) } \\
\hline Range & $20-56$ & $23-52$ \\
\hline Mean \pm SD & $37.59 \pm 8.84$ & $38.75 \pm 7.23$ \\
\hline \multicolumn{3}{|l|}{ Gender } \\
\hline Male & $15(32.6 \%)$ & $19(39.6 \%)$ \\
\hline Female & $31(67.4 \%)$ & $29(60.4 \%)$ \\
\hline \multicolumn{3}{|c|}{ Follow-up, months } \\
\hline Range & $6-30$ & $6-32$ \\
\hline Mean $\pm S D$ & $20.24 \pm 7.39$ & $19.02 \pm 5.03$ \\
\hline \multicolumn{3}{|c|}{ VAS back (preoperative) } \\
\hline Range & $5-9$ & $5-9$ \\
\hline Mean \pm SD & $7.00 \pm 1.26$ & $7.25 \pm 1.28$ \\
\hline \multicolumn{3}{|c|}{ VAS leg (preoperative) } \\
\hline Range & $4-9$ & $4-9$ \\
\hline Mean \pm SD & $7.39 \pm 1.24$ & $6.75 \pm 1.28$ \\
\hline \multicolumn{3}{|c|}{ ODI (preoperative) } \\
\hline Range & $34-79$ & $32-77$ \\
\hline Mean \pm SD & $55.37 \pm 13.05$ & $51.42 \pm 12.45$ \\
\hline \multicolumn{3}{|c|}{ Grade of spondylolithesis } \\
\hline Grade I & 25 cases $(54.3 \%)$ & 32 cases $(66.7 \%)$ \\
\hline Grade II & 21 cases $(45.7 \%)$ & 16 cases $(33.3 \%)$ \\
\hline \multicolumn{3}{|c|}{ Type of spondylolithesis, $n$ (\%) } \\
\hline Degenerative & 27 cases $(58.7 \%)$ & 25 cases $(50 \%)$ \\
\hline Isthmic & 19 cases $(41.3 \%)$ & 23 cases $(50 \%)$ \\
\hline \multicolumn{3}{|l|}{ Affected level } \\
\hline L3-L4 & $4(8.7 \%)$ & $3(6.2 \%)$ \\
\hline L4-L5 & $25(54.3 \%)$ & $31(64.6 \%)$ \\
\hline L5-S1 & 17 (37\%) & $14(29.2 \%)$ \\
\hline
\end{tabular}

pedicle screw fixation and cage placement. The wound was profusely irrigated and closed in layers.

\section{TLIF}

A midline skin incision was performed. The muscles and soft tissues were retracted to expose the lateral aspect of the spinous process, the lamina, and the facet joint. Based on the clinical presentation, a unilateral laminectomy and partial facetectomy were performed on the side consistent with the patient's symptoms. A bilateral laminectomy was done only for clinically significant bilateral neural element compression. After adequate decompression of the neural elements has been performed, bilateral pedicle screws were placed in the standard fashion. Distraction of the disc space was performed using the four pedicle screws, and complete discectomy was done from one side using rongeurs and disc shavers. 
The bone chips obtained from laminectomy were inserted to fill the anterior third of the disc space, then a kidney-shaped cage filled with iliac bone graft was placed into the disc space. After insertion of bone grafts in both groups, the screws were tightened to the lordotic rod. Distraction or compression was added to achieve a good reduction in a proper lordotic curve. A closed drainage system was inserted in all cases, and wound closure was performed in layers.

\section{Perioperative, clinical, and radiological assessments}

The study assessed perioperative results related to the operative procedure such as blood loss, operation time, hospital stay, and complications within 1 month postoperatively. Oswestry Disability Index (ODI) Questionnaires [15] were administered for functional evaluation, and the visual analog scale (VAS) [16] was used to assess pain preoperatively and postoperatively. Moreover, the same clinical parameters together with neurologic examination were evaluated at follow-up visits, which were scheduled 3,6 , and 12 months after the operation.

Radiographic evaluation included preoperative X-rays (standard lumbar anteroposterior/lateral, flexion/extension views), computed tomography (CT), and magnetic resonance imaging (MRI).

Lumbosacral spine plain X-ray, including anteroposterior and lateral views, was obtained in all cases within $72 \mathrm{~h}$ after surgery to evaluate the position of screws and the cage. Static and dynamic radiographs were obtained 3 and 6 months postoperatively. All patients underwent repeat X-ray and CT scan 1 year postoperatively. We compared pre- and postoperative radiographs. For the analysis, the postoperative radiographs included only the final radiograph at a minimum of 6 months after surgery.

The focus was to evaluate three radiographic characteristics at follow-up: (1) percentage of slip and percentage of reduction, (2) cage and screws position, and (3) fusion rate.

The degree of spondylolisthesis was measured as a percentage of the distance from the posterior border of the caudal vertebra to the posterior border of the rostral vertebra, normalized to the superior end plate diameter of the former (Fig. 1). Slip reduction was defined as the difference between the pre- and postoperative spondylolisthesis. The reduction rate was calculated as follows:

Preoperative slippage distance-postoperative slippage distance Preoperative slippage distance

Fusion rates were assessed with the Bridwell grading system by the final radiograph at a minimum of 6

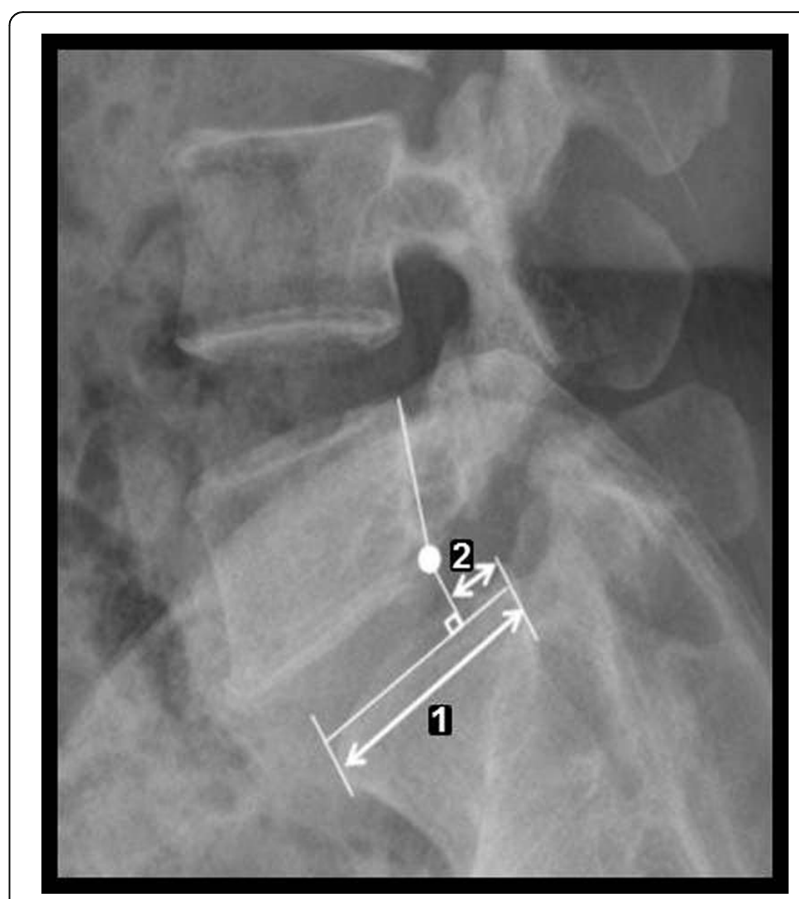

Fig. 1 Degree of spondylolisthesis (\%) = distance (2)/distance (1) $\times$ $100 \%$. The spondylolisthesis degree was measured as a percentage of the distance from the posterior border of the caudal vertebra to the posterior border of the rostral vertebra, normalized to the superior end plate diameter of the former

months after surgery. The Bridwell system is composed of the following categories and grades [17]: Grade I: fused with remodeling and trabeculae present, grade II: graft intact but not fully remodeled and incorporated, with no lucencies above or below, grade III: graft intact but with a definite lucency at the top or bottom of the graft, and grade IV: definitely not fused, with resorption of bone graft and collapse. Both grades I and II were considered radiographic signs of solid fusion, and the fusion condition at the last follow-up was collected for analysis.

The criteria used to prove solid fusion inpatients were Trabeculae seen bridging the interbody gap with isodense bone in the cage and the adjacent vertebral bodies, anteriorand/or posterior sentinel signs, no lucencies around the pedicle screws, no lucencies around the cages, Integration of the cage with the endplates and silhouetting of the cage, and no evidence of motion on dynamic flexion and extension X-rays.

\section{Statistical analysis}

Data were expressed as mean \pm standard deviation. Statistical analysis was done using Student $T$ test with IBM SPSS Statistics for Windows, Version 21 (IBM Corp., Armonk, NY). 


\section{Results}

\section{Clinical outcome}

There were significant differences between the groups in relation to VAS for back pain and ODI. These variables were significantly higher in the TLIF group compared to the PLIF group. There was no significant difference between the two groups with respect to VAS for leg pain at final follow-up (Table 2).

\section{Surgical time and blood loss}

Estimated blood loss and operative time in the TLIF group were significantly lower than those in the PLIF group $(P<0.05)$ (Table 2$)$.

\section{Reduction and fusion results}

At the time of the last follow-up, both groups had similar slip reduction, and spinal fusion rates $(P>.05)$. Spondylolisthesis slip reduction rate was $51.7913 .59 \%$ in the TLIF group and $64.6810 .87 \%$ in the PLIF group $(P=$ 0.116). Solid fusion (Bridwell fusion grades I or II) was achieved in all patients (Figs. 2 and 3). In total, 32 out of 46 patients $(66.7 \%)$ in the TLIF group and 31 out of 48 (67.4\%) patients in the PLIF group achieved grade I fusion, and all others achieved grade II fusion (Table 3).

\section{Operative and postoperative complications}

In the PLIF group, there were five complications: two dural tears (repaired primarily), two neurologic deficit (postoperative weakness of great toe dorsiflexion, which was relieved spontaneously), and one deep wound infection (managed with debridement, drains, and intravenous antibiotics).
A superficial infection was diagnosed in two patients in the TLIF group, which was treated conservatively. In the TLIF group, one patient experienced a dural tear without neurologic symptoms (repaired primarily).

All these complications did not lead to irreversible sequelae. No perioperative complications in either group required revision surgery (Table 2).

\section{Discussion}

Spondylolisthesis, either degenerative or isthmic type, is usually associated with radicular symptoms and back pain due to instability and compression $[18,19]$, but surgical treatment of spondylolisthesis not only depends on decompression of neural tissue and stabilization of motion segment but also reconstitution of disc space height and restoration of sagittal plane translational and rotational alignment are essential [20].

Interbody fusion is commonly used in surgical treatment of low-grade spondylolisthesis as it achieves solid fusion, preserves the disc height, maintains the load-bearing capacity, and reconstructs the anterior column after disc evacuation [21-23].

PLIF or TLIF can achieve circumferential spinal stabilization by a single posterior approach [24], but TLIF usually requires unilateral exposure with less operative time and blood loss [25]. In the current study, both the operative time and blood loss in PLIF was significantly higher compared to TLIF $(p=0.0004$ and 0.0001 , respectively). Liu et al. [26] have similarly reported that both the intraoperative time and blood loss volume were higher in the PLIF group than those of the TLIF group. This might be attributed to the necessity if

Table 2 Comparison of surgical outcomes between PLIF and TLIF

\begin{tabular}{|c|c|c|c|}
\hline Parameters & PLIF group $(n=46)$ & TLIF group $(n=48)$ & $P$ value \\
\hline Operation time (minutes) & $127.39 \pm 21.62$ & $114.48 \pm 13.26$ & 0.0004 \\
\hline Blood loss $\left(\mathrm{cm}^{3}\right)$ & $456.96 \pm 120.74$ & $366.15 \pm 78.49$ & 0.0001 \\
\hline VAS back pre & $7.00 \pm 1.26$ & $7.25 \pm 1.28$ & 0.1717 \\
\hline VAS back post & $2.26 \pm 1.00$ & $1.77 \pm 0.75$ & 0.0044 \\
\hline VAS back change & $4.74 \pm 1.14$ & $5.40 \pm 1.18$ & 0.0037 \\
\hline VAS leg pre & $7.39 \pm 1.24$ & $7.17 \pm 1.36$ & 0.1752 \\
\hline VAS leg post & $3.24 \pm 1.18$ & $2.98 \pm 0.91$ & 0.0824 \\
\hline VAS leg change & $4.15 \pm 1.44$ & $4.19 \pm 1.41$ & 0.4245 \\
\hline ODI pre & $51.42 \pm 12.45$ & $55.37 \pm 13.05$ & 0.0684 \\
\hline ODI post & $16.85 \pm 4.44$ & $17.67 \pm 7.33$ & 0.2581 \\
\hline ODI change & $33.98 \pm 10.40$ & $37.70 \pm 10.61$ & 0.0449 \\
\hline Postoperative complications (number of cases) & 5 & 3 & \\
\hline Dural tear & 2 & 1 & \\
\hline Nerve root injury (neurologic deficit) & 2 & 0 & \\
\hline Wound infection & 1 & 2 & \\
\hline
\end{tabular}



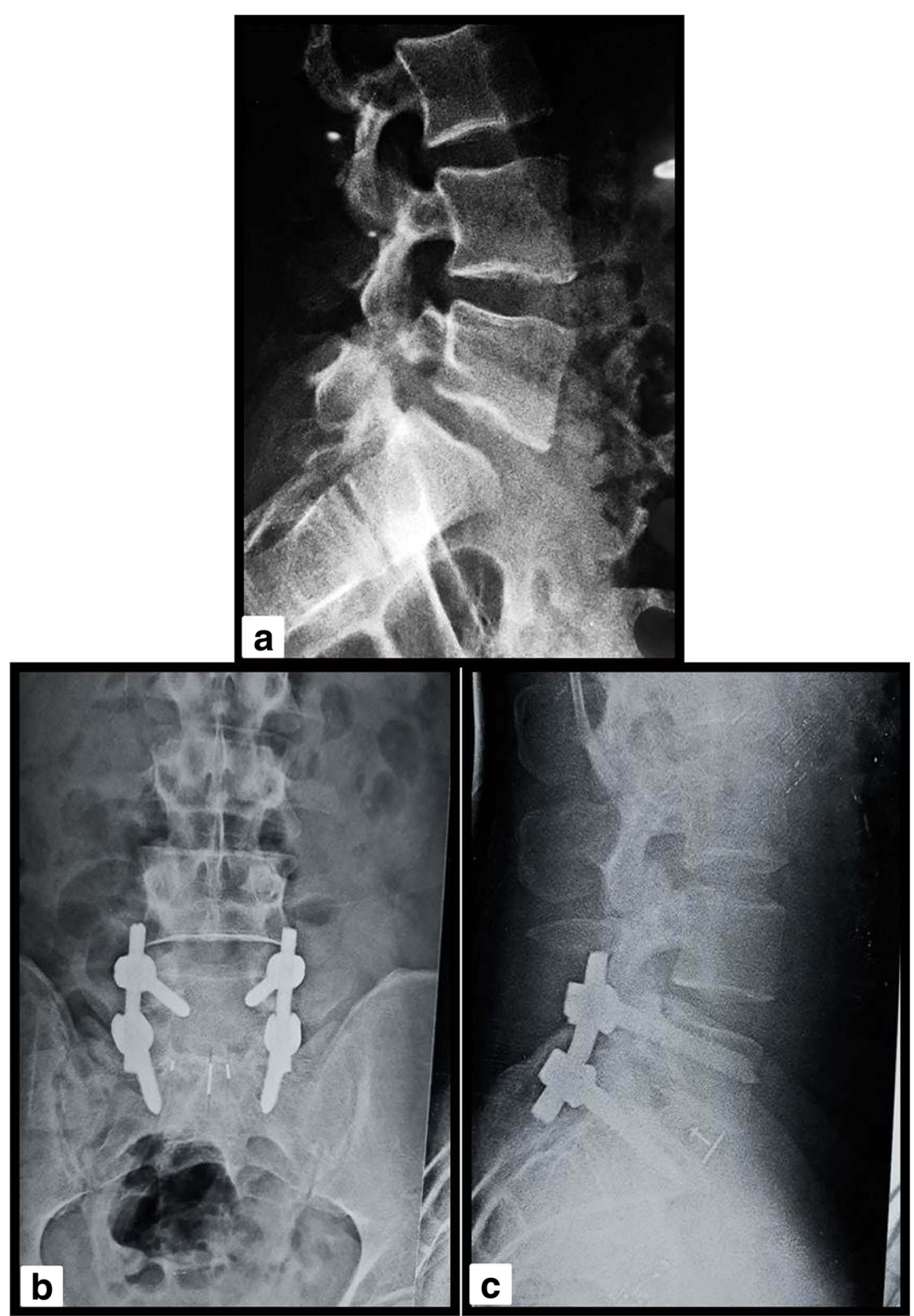

Fig. 2 TLIF procedure for the patient with isthmic L5 S1 spondylolisthesis. a Preoperative X-ray lateral view. b, c Posteroanterior and lateral X-ray films 6 months after surgery. Note the reduction in the anterolisthesis, restoration of disk height, and the visible bone fusion

the bilateral exposure in PLIF compared to the unilateral exposure required in TLIF.

In the present work, the improvement of the VAS for back pain was significantly higher in the TLIF group compared to the PLIF group $(p=0.0037)$. This came in agreement with the work of El-Sayed et al. [27] who reported that the postoperative VAS for back pain was significantly improved in the TLIF group compared to the PLIF group. Nevertheless,
Lars et al. [28] reported that the improvement in VAS was related to the pre-operative pathology, where the isthmic spondylolisthesis showed more improvement in VAS compared to the degenerative type. This might explain the significant VAS for back pain improvement in the current study, as isthmic spondylolisthesis represented $50 \%$ of the TLIF group cases compared to only $41.3 \%$ of the PLIF group. On the other hand, the study of Han et al. [29] showed no 

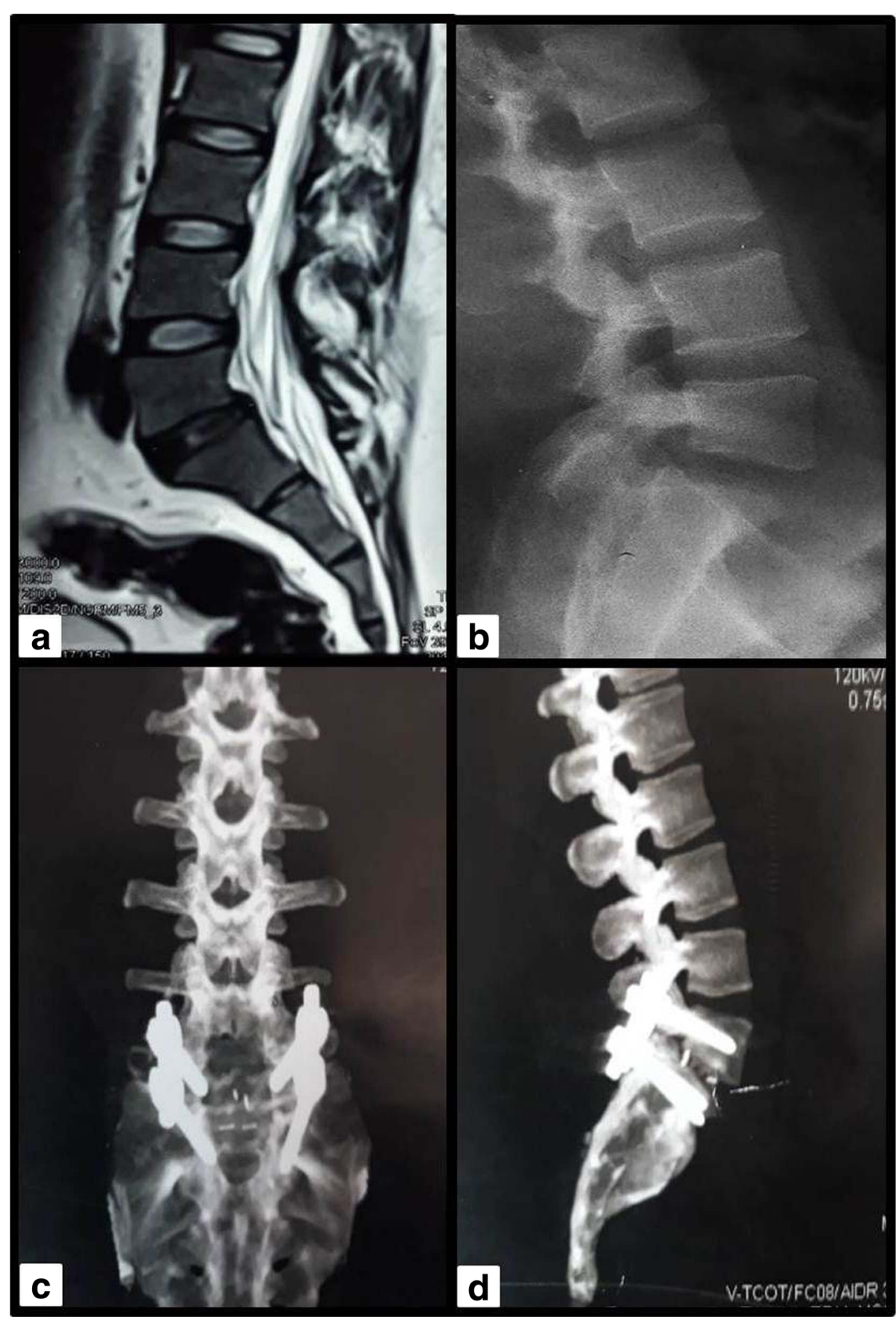

Fig. 3 PLIF procedure for the patient with degenerative L5 S1 spondylolisthesis. a Preoperative MRI. b Preoperative X-ray lateral view. c, d Posteroanterior and lateral X-ray films 6 months postoperatively. Note the reduction in the anterolisthesis and restoration of disk height

statistically significant difference in VAS for pain at any time between the PLIF group and TLIF group.

In the current study, we could report a complication rate of $10.9 \%$ occurring in the PLIF group including a dural tear in $4.4 \%$ of cases, nerve root injury in another $4.4 \%$ of cases, and a deep wound infection in only $2.2 \%$ of them, but in TLIF group, there was a complication rate of only $6.3 \%$ including $4.2 \%$ of cases with a superficial wound infection and $2.1 \%$ of them with a dural injury. Humphreys et al. [30] and Yehya [31] both evaluated the results of PLIF versus TLIF in their studies and reported that the complication rate in PLIF was higher than in TLIF. This might be attributed to the necessity of bilateral exposure and excessive medial retraction of the dura when placing the cage in the PLIF technique, which increases the incidence of neural 
Table 3 Slip reduction and fusion rate of spondylolisthesis

\begin{tabular}{|c|c|c|c|c|}
\hline \multicolumn{2}{|c|}{ Parameters } & PLIF group $(n=46)$ & TLIF group $(n=48)$ & $P$ value \\
\hline \multicolumn{5}{|c|}{ Degree of spondylolisthesis } \\
\hline \multicolumn{2}{|c|}{ Preoperative (\%) } & $22.37 \pm 10.20$ & $18.08 \pm 6.42$ & 0.4968 \\
\hline \multicolumn{2}{|c|}{ Postoperative (\%) } & $8.24 \pm 5.32$ & $8.71 \pm 3.98$ & 0.4511 \\
\hline \multicolumn{2}{|c|}{ Slip reduction (\%) } & $64.68 \pm 10.87$ & $51.79 \pm 13.59$ & 0.1160 \\
\hline \multicolumn{5}{|c|}{ Fusion rate } \\
\hline \multirow[t]{2}{*}{ Grade I } & Number & 31 & 32 & \\
\hline & Rate $\%$ & 67.4 & 66.7 & \\
\hline \multirow[t]{2}{*}{ Grade ॥ } & Number & 15 & 16 & \\
\hline & Rate \% & 32.6 & 33.3 & \\
\hline
\end{tabular}

complications such as nerve injury, dural tear, and epidural scarring [32-34].

In our study, by the time of the last follow-up, both groups showed no significant difference in slip reduction and spinal fusion rate. Solid fusion was achieved in all cases including grade I fusion in $66.7 \%$ of cases in the TLIF group and $67.4 \%$ of cases in the PLIF group. Similarly, Yan et al. [35] in a comparative study between PLIF and TLIF, found that there was no significant difference between both groups in slip reduction rate and that all patients have achieved spinal fusion with no case of cage extrusion. Nevertheless, in the study of Lee et al. [36], after 1 year of follow-up, fusion grade I was achieved in $61.9 \%$ of cases in TLIF group and in $63.3 \%$ in PLIF group without a statistically significant difference between both groups.

\section{Conclusion}

The current study could show that TLIF is superior to PLIF with respect to the functional outcome and the complication rate in grade I/II single-level lumbar spondylolisthesis.

\section{Abbreviations}

BMl: body mass index; ODI: Oswestry Disability Index Questionnaires; PLIF: posterior lumbar interbody fusion; TLIF: transforaminal lumbar interbody fusion; VAS: visual analog scale

\section{Acknowledgements}

The authors sincerely thank the head of the Neurosurgery Department, Tanta Faculty of Medicine [Professor Ali Seif Eldeen] for his advice and support during performing the current work.

\section{Authors' contributions}

All authors have equally participated in designing the work and operating the patients. AE and IS have equally performed the data acquisition and analysis. ER has done the data interpretation and the scientific writing. All authors have thoroughly read, revised, and approved the final submitted manuscript.

\section{Funding}

The authors have no support or funding to report.

\section{Availability of data and materials}

The datasets used and/or analyzed during the current study are available from the corresponding author on reasonable request.

\section{Ethics approval and consent to participate}

Ethics approval was provided by the local Ethical Committee of the Faculty of Medicine, Tanta University. Reference number 32769 was obtained on the 26th of December 2018. Consent for participation was not applicable as this is a retrospective study, so the ethical committee waived the consent to participate.

\section{Consent for publication}

Not applicable

\section{Competing interests}

The authors declare that they have no competing interests.

Received: 29 December 2018 Accepted: 1 August 2019

Published online: 12 August 2019

\section{References}

1. Lastfogel JF, Altstadt TJ, Rodgers RB, Horn EM. Sacral fractures following stand-alone L5-S1 anterior lumbar interbody fusion for isthmic spondylolisthesis. J Neurosurg Spine. 2010;13:288-93.

2. Butt MF, Dhar SA, Hakeem I, Faroog M, Halwai MA, Mir MR, Kangu KA. In situ instrumented posterolateral fusion without decompression in symptomatic low-grade isthmic spondylolisthesis in adults. Int Orthop. 2008; 32:663-9.

3. Sivaraman A, Altaf F, Jalgaonkar A, Kakkar R, Sirigiri PB, Howieson A, Crawford RJ. Prospective study of posterior lumbar interbody fusion with either interbody graft or interbody cage in the treatment of degenerative spondylolisthesis. J Spinal Disord Tech. 2015;28:E467-71.

4. Ha KY, Na KH, Shin JH, Kim KW. Comparison of posterolateral fusion with and without additional posterior lumbar interbody fusion for degenerative lumbar spondylolisthesis. J Spinal Disord Tech. 2008;21:229-34.

5. Gjessing MH. Osteoplastic anterior fusion of the lower lumbar spine in spondylolisthesis, localized spondylosis, and tuberculous spondylitis. Acta Orthop Scand. 1951;20:200-13.

6. Cloward RB. Spondylolisthesis: treatment by laminectomy and posterior interbody fusion. Clin Orthop Relat Res. 1981;154:74-82.

7. Schnee CL, Freese A, Ansell LV. Outcome analysis for adults with spondylolisthesis treated with posterolateral fusion and transpedicular screw fixation. J Neurosurg. 1997;86:56-63.

8. Noggle JC, Sciubba DM, Samdani AF, Anderson DG, Betz RR, Asghar J. Minimally invasive direct repair of lumbar spondylolysis with a pedicle screw and hook construct. Neurosurg Focus. 2008;25:E15.

9. Tsutsumimoto T, Shimogata M, Ohta H, Misawa H. Miniopen versus conventional open posterior lumbar interbody fusion for the treatment of lumbar degenerative spondylolisthesis: comparison of paraspinal muscle damage and slip reduction. Spine (Phila Pa 1976). 2009;34:1923-8.

10. Cloward RB. The treatment of ruptured lumbar intervertebral disc by vertebral body fusion. III. Method of use of banked bone. Ann Surg. 1952; 136:987-92.

11. Lin PM. A technical modification of Cloward's posterior lumbar interbody fusion. Neurosurgery. 1977:1:118-24.

12. Harms J, Rolinger $\mathrm{H}$. A one-stager procedure in operative treatment of spondylolistheses: dorsal traction-reposition and anterior fusion (author's transl). Z Orthop Ihre Grenzgeb. 1982;120:343-7.

13. Mobbs RJ, Phan K, Malham G, Seex K, Prashanth J. Rao Lumbar interbody fusion: techniques, indications and comparison of interbody fusion options including PLIF, TLIF, MI-TLIF, OLIF/ATP, LLIF and ALIF. J Spine Surg. 2015;1:1.

14. Djurasovic M, Bratcher KR, Glassman SD, Dimar JR, Carreon LY. The effect of obesity on clinical outcomes after lumbar fusion. Spine (Phila Pa 1976). 2008;33(16):1789-92.

15. Fairbank JC, Pynsent PB. The Oswestry Disability Index. Spine (Phila Pa 1976) 2000:25(22):2940-52.

16. Wewrs M, Lowe NA. Critical review of visual analogue scales in the measurement of clinical phenomena. Res Nurs Health. 1990;13:227-36.

17. Bridwell KH, Lenke LG, McEnery KW, Baldus C, Blanke K. Anterior fresh frozen structural allografts in the thoracic and lumbar spine: do they work if combined with posterior fusion and instrumentation in adult patients with kyphosis or anterior column defects? Spine. 1995;20:1410-8.

18. Agabegi SS, Fischgrund JS. Contemporary management of isthmic spondylolisthesis: pediatric and adult. Spine J. 2010;10:530-43. 
19. Wu CH, Wong CB, Chen LH, Niu CC, Tsai TT, Chen WJ. Instrumented posterior lumbar interbody fusion for patients with degenerative lumbar scoliosis. J Spinal Disord Tech. 2008;21:310-5.

20. Spruit M, Pavalov PW, Leitao J, De Kleuver M, Anderson PG, Den Boer F. Posterior reduction and anterior lumbar interbody fusion in sympathetic low grade adult isthmic spondylolisthesis: a short term radiological and functional outcome. Eur Spine J. 2002;11:428-33.

21. Videbaek TS, Christensen FB, Soegaard R, Hansen ES, Høy K, Helmig P, Niedermann B, Eiskjoer SP, Bünger CE. Circumferential fusion improves outcome in comparison with instrumental posterolateral fusion: long-term results of a randomized clinical trial. Spine. 2006:31:2875-80.

22. Kwon BK, Hilibrand AS, Malloy K, Savas PE, Silva MT, Albert TJ, Vaccaro AR. A clinical analysis of the literature regarding surgical approach and outcome for adult low-grade isthmic spondylolisthesis. J Spinal Disord Tech. 2005; 18(Suppl:S30-40

23. Stonecipher T, Wright S. Lumbar interbody fusion with facet-screw fixation. Spine. 1989;14:468-71.

24. Know BK, Berta S, Daffner SD, Vaccaro AR, Hilibrand AS, Grauer JN, Beiner J, Albert TJ. Radiographic analysis of transforaminal lumbar interbody fusion for the treatment of adult isthmic spondylolisthesis. J Spinal Disord Tech. 2003;16:469-76.

25. Chastain CA, Eck JC, Hodges SD, Levi P. Transforaminal lumbar interbody fusion: a retrospective study of long-term pain relief and fusion outcomes. Orthopedics. 2007;30:389-92.

26. Liu J, Deng H, Long X, Chen X, Xu R, Liu Z. A comparative study of perioperative complications between transforaminal versus posterior lumbar interbody fusion in degenerative lumbar spondylolisthesis. Eur Spine J. 2016;25:1575-80.

27. El-Sayed AA, El-Qazaz MY, Mohamed KE, Shater MS. Evaluation of transforaminal lumbar interbody fusion versus posterior lumbar interbody fusion in patients of lumbar instability submitted to transpedicular screws fixation. Med J Cairo Univ. 2012;80(1):185-92.

28. Hackenberg L, Halm H, Bullmann V, Vieth V, Schneider M, Liljenqvist U. Transforaminal lumbar interbody fusion: a safe technique with satisfactory three to five years results. Eur Spine J. 2005;14:551-8.

29. Han SY, Xiao Q, Zhu GT, Dai J, Tang XM, Sun HL. Comparison between transforaminal lumbar interbody fusion and posterior lumbar interbody fusion in treatment of lumbar spondylolisthesis. Int J Clin Exp Med. 2016; 9(2):3932-8.

30. Humphreys SC, Hodges SD, Patwardhan AG, Eck JC, Murphy RB, Covington LA. Comparison of posterior and transforaminal approaches to lumbar interbody fusion. Spine. 2001;26:567-71.

31. Yehya A. TLIF versus PLIF in management of low grade spondylolisthesis. Bull Alex Fac Med. 2010;46(2):127-33.

32. Talia AJ, Wong ML, Lau HC, Kaye AH. Comparison of the different surgical approaches for lumbar interbody fusion. J Clin Neurosci. 2015;22(2):243-51.

33. DiPaola CP, Molinari RW. Posterior lumbar interbody fusion. J Am Acad Orthop Surg. 2008:16(3):130-9.

34. Hosono N, Namekata M, Makino T, Miwa T, Kaito T, Kaneko N, Fuji T. Perioperative complications of primary posterior lumbar interbody fusion for non-isthmic spondylolisthesis: analysis of risk factors. J Neurosurg Spine. 2008;9(5):403-7.

35. Yan DL, Pei FX, Li J, Soo CL. Comparative study of PLIF and TLIF treatment in adult degenerative spondylolisthesis. Eur Spine J. 2008;17:1311-6.

36. Lee N, Kim KN, Yi S, Ha Y, Shin DA, Yoon DH, Kim KS. Comparison of outcomes of anterior, posterior, and transforaminal lumbar interbody fusion surgery at a single lumbar level with degenerative spinal disease. World Neurosurg. 2017;101:216-26.

\section{Publisher's Note}

springer Nature remains neutral with regard to jurisdictional claims in published maps and institutional affiliations.

\section{Submit your manuscript to a SpringerOpen ${ }^{\circ}$ journal and benefit from:}

- Convenient online submission

- Rigorous peer review

- Open access: articles freely available online

High visibility within the field

- Retaining the copyright to your article

Submit your next manuscript at $\boldsymbol{\nabla}$ springeropen.com 